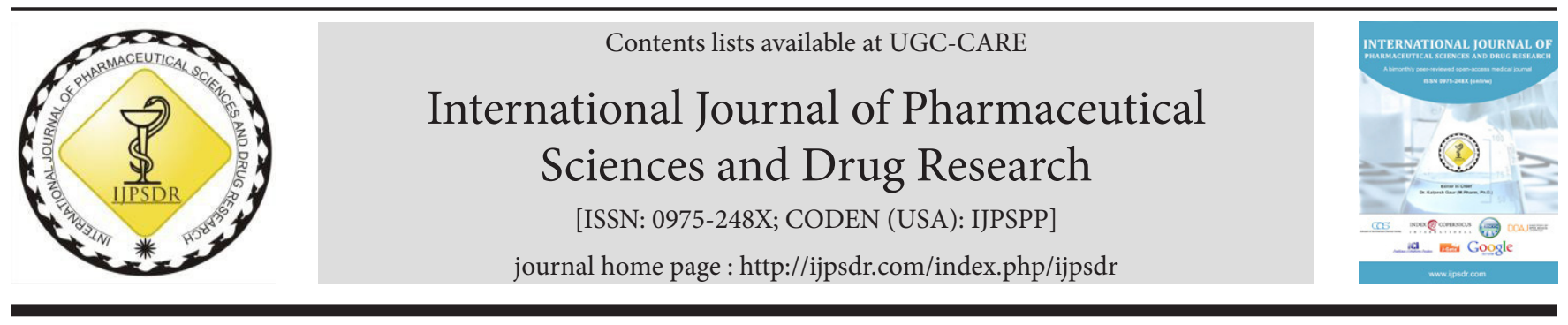

Research Article

\title{
Formulation and Evaluation of Fast Dissolving Oral Films incorporated with Ramipril and $\beta$-Cyclodextrin Complex
}

\author{
Puttaswamy Nirmala* \\ Department of Pharmaceutics, Government College of Pharmacy, Bengaluru-560027, Karnataka, India
}

\begin{tabular}{l} 
A R T I C L E I N F O \\
\hline Article history: \\
Received: 28 April, 2020 \\
Revised: 11 June, 2020 \\
Accepted: 26 June, 2020 \\
Published: 30 July, 2020 \\
Keywords: \\
Anti-hypertensive agent, \\
ß-cyclodextrin, \\
Fast dissolving oral film (FDOF), \\
Ramipril. \\
D0I: \\
10.25004/IJPSDR.2020.120412
\end{tabular}

\section{INTRODUCTION}

Drug delivery by oral route is mostly the favored administration route owing to patient compliance, and convenience in achievement of systemic and local effects. Parenteral, intranasal, transdermal, pulmonary, and buccal apart from oral route can achieve systemic delivery of drugs. In general, there is no ideal absorption route for drug delivery that can match the physiological requirements. But keeping in mind the surface area, contact time, low metabolic activity, high blood supply, lack of variability, accessibility, and permeability relatively oral route can be said to have beneficial characteristics for drug absorption. At present, about $80 \%$ of the medications are given by oral route of which tablets, capsules, and granules are most prescribed dosage forms. Thus, a need for advancement of oral drug delivery systems is required to achieve enhanced therapeutic efficacy and safety of the treatment. Overall, majority of the pharmaceutical market is occupied by oral dosage forms owing to their safety, efficacy, economic, and consumer compliance in comparison to other routes. Also, regulatory restrictions, technical barriers on parenteral, injectables, and inhalation routes again flip the coin towards oral route as they are economic, making their availability to broader range of compounds. ${ }^{[1]}$

The requirement of enhanced bioavailability, with quicker onset of action and subject compliance, pave the way for novel oral dosage forms. Of them, FDOF formulated using super disintegrates and hydrophilic ingredients are coming into picture. This system is comprised of a very thin film that placed on tongue or other oral mucosal tissue, followed by hydration with saliva and adherence to the

\footnotetext{
${ }^{*}$ Corresponding Author: Puttaswamy Nirmala

Address: Department of Pharmaceutics, Government College of Pharmacy, Bengaluru-560027, Karnataka, India

Email $ه:$ nirmalagcp78@gmail.com

Tel.: +91-9036648678

Relevant conflicts of interest/financial disclosures: The authors declare that the research was conducted in the absence of any commercial or financial relationships that could be construed as a potential conflict of interest.

Copyright (C) 2020 Puttaswamy Nirmala. This is an open access article distributed under the terms of the Creative Commons AttributionNonCommercial-ShareAlike 4.0 International License which allows others to remix, tweak, and build upon the work non-commercially, as long as the author is credited and the new creations are licensed under the identical terms.
} 
site of action. It thereby undergoes quick disintegration releasing the drug that undergoes instant absorption into systemic circulation via buccal mucosa. ${ }^{[2-4]}$

Ramipril is a new generation anti-hypertensive drug and is an ACE inhibitor. Ramipril is a prodrug/ precursor, which is converted into active metabolite 'ramiprilat' in liver by carboxylesterase. Ramipril inhibits the actions of ACE, lowering the production of angiotensin II. ${ }^{[5]}$ This leads to relaxation in arteriole smooth muscle leading to a reduction in total peripheral resistance and blood pressure. The major problems encountered with this drug are poor aqueous solubility, undergoes first-pass metabolism, and poor bioavailability (28-30\%) after oral administration. For efficient management of hypertension in geriatric patients, it is advisable to formulate ramipril into fast dissolving oral films for effective drug delivery. ${ }^{[6]}$

The current work is aimed at enhancing the solubility and fast action of ramipril by formation of inclusion complex with $\beta-\mathrm{CD}$, followed by formulation into $\mathrm{FDOF}^{[7,8]}$

\section{Materials AND METhods}

\section{Materials}

Ramipril obtained from Aurobindo Pharma Ltd., Hyderabad, and marketed product was purchased. $\beta-C D$, HPMC E15, chitosan, PEG 400 crospovidone, sodium starch glycolate, and citric acid were procured from MSN Lab, Hyderabad, India.

\section{Methods}

Preparation of Ramipril Inclusion Complex with $\beta$-CD

Inclusion complex of ramipril prepared by kneading method. The mixture of ramipril: $\beta$-CD in varying ratios of 1:0.5 (IC1), 1:1 (IC2), and 1:2 (IC3) wetted in mortar with carbinol and water (1:1). This wet mass kneaded thoroughly generates paste consistency, followed by drying at room temperature. The dry mass sieved through sieve\# 80 , stored in a desiccator for future use. ${ }^{[9]}$

\section{Formulation of Ramipril FDOF}

The ramipril FDOF prepared from IC2 formulation (ramipril $2.5 \mathrm{mg}: \beta$-CD $2.5 \mathrm{mg}$ ) by adopting solvent casting method with hydroxypropyl methylcellulose (HPMC) $15 \mathrm{cps} / \mathrm{chitosan}$, acting as film-forming polymer. Weighed quantity of polymer mixed with a three-fourth volume of water with continuous stirring, followed by incorporation of inclusion complex containing ramipril. Sodium starch glycolate/ crospovidone (super disintegrants) added to contents and stirred continuously, followed by addition of citric acid and PEG 400, final volume adjusted to $15 \mathrm{~mL}$, using distilled water. The resultant bubble-free viscous solution cast on the Petri dish (area of $63.85 \mathrm{~cm}^{2}$ ), placed in hot air oven at $40^{\circ} \mathrm{C}$ for 24 hours (Table 1). The obtained films cut into $2 \times 2 \mathrm{~cm}^{2}$ pieces, containing $2.5 \mathrm{mg}$ of ramipril, wrapped in aluminum foils, and stored in desiccator. ${ }^{[10]}$

\section{Evaluation of Inclusion Complex}

Drug content and in vitro drug release of inclusion complex: The inclusion complex comprising $2.5 \mathrm{mg}$ of ramipril taken into $50 \mathrm{~mL}$ standard flask, solubilized in carbinol, and diluted suitably using phosphate buffer ( $\mathrm{pH}$ 6.8). The resultant filtered and filtrate analyzed spectrophotometrically (Shimadzu UV-1201, Japan) at $210 \mathrm{~nm}^{[11]}$

The in vitro dissolution study conducted in USP dissolution testing apparatus type-II (EDT-08Lx, Electrolab, Mumbai, India). The complex comprising

Table 1: Composition of ramipril FDOF

\begin{tabular}{|c|c|c|c|c|c|c|c|c|c|}
\hline \multicolumn{10}{|c|}{ Ingredients } \\
\hline $\begin{array}{l}\text { Formulation } \\
\text { code }\end{array}$ & $\begin{array}{l}\text { Inclusion complex } \\
\text { equivalent to } \\
5 \mathrm{mg} \text { of drug } \\
(\mathrm{mg})\end{array}$ & $\begin{array}{l}\text { HPMC } 15 \\
\text { cps } \\
(\mathrm{mg})\end{array}$ & $\begin{array}{l}\text { Chitosan } \\
(\mathrm{mg})\end{array}$ & $\begin{array}{l}\text { Sodium starch } \\
\text { glycolate } \\
(\mathrm{mg})\end{array}$ & $\begin{array}{l}\text { Crospovidone } \\
(\mathrm{mg})\end{array}$ & $\begin{array}{l}\text { Citric acid } \\
(\mathrm{mg})\end{array}$ & $\begin{array}{l}\text { Aspertame } \\
(\mathrm{mg})\end{array}$ & $\begin{array}{l}\text { PEG } 400 \\
(\mathrm{mg})\end{array}$ & $\begin{array}{l}\text { Distilled } \\
\text { water up } \\
\text { to } \\
(\mathrm{mL})\end{array}$ \\
\hline F1 & 80 & 250 & - & 20 & - & 30 & 8 & 40 & 10 \\
\hline F2 & 80 & 250 & - & 40 & - & 30 & 8 & 40 & 10 \\
\hline F3 & 80 & 250 & - & 60 & - & 30 & 8 & 40 & 10 \\
\hline F4 & 80 & 250 & - & - & 20 & 30 & 8 & 40 & 10 \\
\hline F5 & 80 & 250 & - & - & 40 & 30 & 8 & 40 & 10 \\
\hline F6 & 80 & 250 & - & - & 60 & 30 & 8 & 40 & 10 \\
\hline F7 & 80 & 250 & 250 & 20 & - & 30 & 8 & 40 & 10 \\
\hline F8 & 80 & - & 250 & 40 & - & 30 & 8 & 40 & 10 \\
\hline F9 & 80 & - & 250 & 60 & - & 30 & 8 & 40 & 10 \\
\hline F10 & 80 & - & 250 & - & 20 & 30 & 8 & 40 & 10 \\
\hline F11 & 80 & - & 250 & - & 40 & 30 & 8 & 40 & 10 \\
\hline $\mathrm{F} 12$ & 80 & - & 250 & - & 60 & 30 & 8 & 40 & 10 \\
\hline
\end{tabular}


about $100 \mathrm{mg}$ of ramipril dissolved in $900 \mathrm{~mL}$ dissolution medium (phosphate buffer of $\mathrm{pH}$ 6.8), maintained at $37 \pm 0.5^{\circ} \mathrm{C}$ and $50 \mathrm{rpm} .5 \mathrm{~mL}$ of resultant sample withdrawn at various time intervals and samples replaced with an equal amount of fresh medium each time. The samples filtered, diluted with dissolution medium, and analyzed spectrophotometrically at $210 \mathrm{~nm} .^{[12]}$

\section{Evaluation of Ramipril FDOF}

FDOFs evaluated for weight variation, moisture content, drug content transparency, thickness of film, disintegration time, folding endurance, tensile strength, surface $\mathrm{pH}$, and percent elongation, as per the procedure given in references. ${ }^{[13-15]}$

\section{In vitro Dissolution Study of Ramipril FDOF}

The dissolution study was conducted in phosphate buffer pH 6.8 (300 mL), as a dissolution medium, using USP dissolution apparatus XXIV (Electrolab, Mumbai, India) maintained at a temperature of $37 \pm 0.5^{\circ} \mathrm{C}$, and peddling speed of $50 \mathrm{rpm} .4 \mathrm{~cm}^{2}$ of each ramipril FDOF placed on stainless-steel wire mesh with sieve size $700 \mu \mathrm{m}$ and inundated into dissolution medium. Samples withdrawn at specified time intervals, filtered, and analyzed spectrophotometrically at $210 \mathrm{~nm}$. The sample's actual volume is maintained by adding equal amounts of fresh dissolution medium. The analysis performed in triplicate for all the formulations. ${ }^{[16]}$

\section{Drug Excipient Compatibility Study by FTIR}

FTIR (Schimadzu IR Affinity 1 spectrophotometer) was used to record the FTIR spectra of pure ramipril and ramipril FDOF in 4,000 to $400 \mathrm{~cm}^{-1}$ range. ${ }^{[17]}$

\section{Scanning Electron Microscopy (SEM) Studies}

The SEM studies carried out using JEOL JEM 2100 F, USA HITACHI, and S-3700N. ${ }^{[18]}$

\section{Stability Studies}

Stability testing was conducted in accordance with ICH guidelines for 6 months in stability chamber (Thermo Lab, Mumbai). Samples were withdrawn at predetermined intervals $0,30,60$, and 90 day's period. The drug content and in vitro release data evaluated. ${ }^{[19]}$

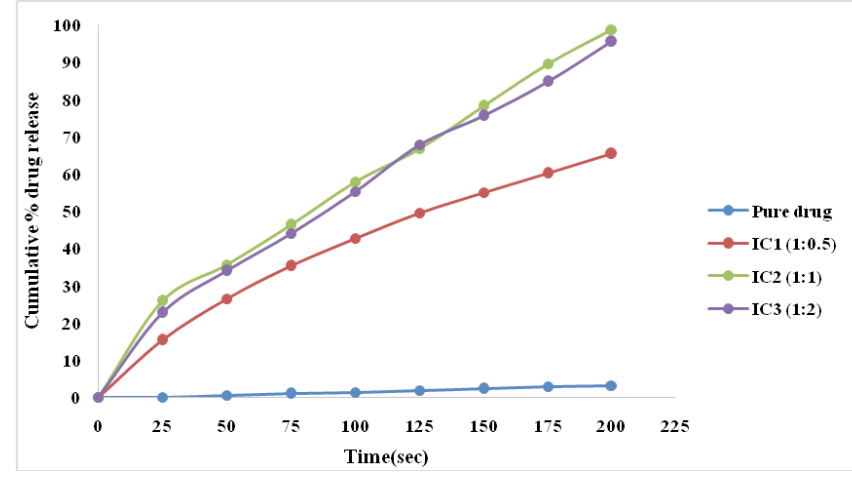

Fig. 1: In vitro drug release of ramipril and inclusion complexes

\section{RESULTS}

\section{Drug Content and In vitro Drug Release of Ramipril Inclusion Complex}

The higher drug content of $95.72 \pm 0.63 \%$ observed for formulation IC2 that comprises drug and $\beta-C D$ in 1:1 ratio (Table 2 ).

In vitro drug release of ramipril and inclusion complexes are displayed in Fig. 1. The maximum dissolution from complex occurred within 200 seconds. The formulation IC 2 comprising equimolar drug and $\beta-C D$, exhibited a maximum dissolution rate of $98.77 \%$ within 180 seconds, while pure drug showed only $3.08 \%$ at the end of 200 seconds.

\section{Preparation of Ramipril FDOF}

Twelve formulations of ramipril FDOF prepared, as per the ingredients listed in Table 1. All films appeared bubble-free, uniform, and appeared clear (Fig. 2).

\section{Evaluation of Ramipril FDOF}

\section{Weight Variation}

The data indicate that formulation F1 exhibited least weight variation of $108.1 \pm 0.51 \mathrm{mg}$, and $\mathrm{F} 9$ maximum value of $110.6 \pm 0.49 \mathrm{mg}$. All the values are within the pharmacopoeial limit (Table 3).

\section{Transparency}

All the ramipril FDOFs were clear in appearance without any air bubbles (Table 3 ).

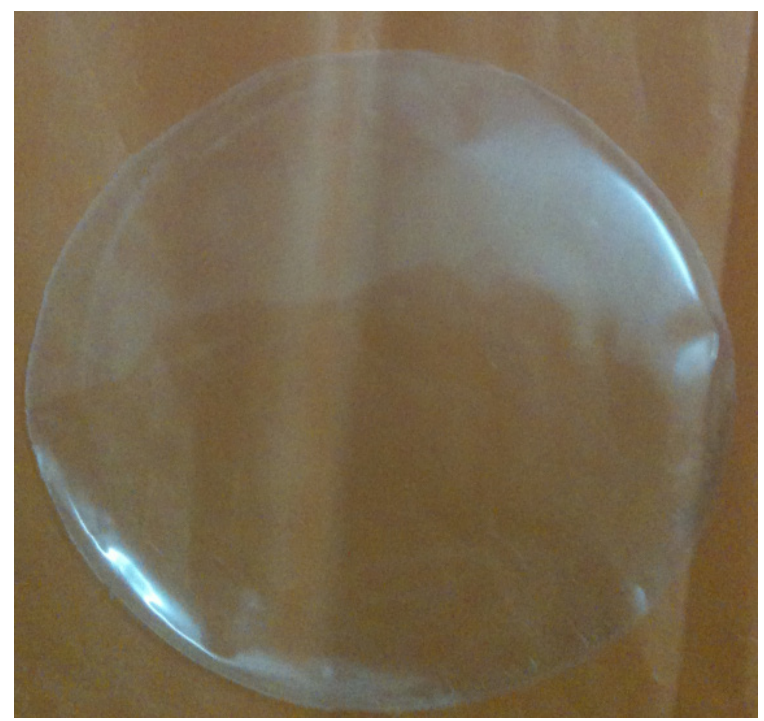

Fig. 2: Preparation of ramipril FDOF

Table 2: \% drug content of inclusion complex of ramipril with beta-cyclodextrin

\begin{tabular}{ll}
\hline Inclusion complex code & \% drug content \\
\hline IC1 (1:0.5) & 92.47 \\
IC2 (1:1) & 95.72 \\
IC3 (1:2) & 93.82 \\
\hline
\end{tabular}


Puttaswamy Nirmala

Table 3: Evaluation parameters of ramipril FDOF

\begin{tabular}{lllll}
\hline Formulation code & $\begin{array}{l}\text { Weight variation } \\
(\mathrm{mg})\end{array}$ & Transparency & $\begin{array}{l}\text { Thickness } \\
(\mathrm{mm})\end{array}$ & $\begin{array}{l}\text { DT } \\
(\mathrm{sec})\end{array}$ \\
\hline F1 & $108.1 \pm 0.51$ & Clear & $0.22 \pm 0.09$ & $15 \pm 0.32$ \\
F2 & $109.2 \pm 0.59$ & Clear & $0.24 \pm 0.04$ & $12 \pm 0.38$ \\
F3 & $110.2 \pm 0.6$ & Clear & $0.248 \pm 0.05$ & $10 \pm 0.3$ \\
F4 & $109.2 \pm 0.49$ & Clear & $0.22 \pm 0.04$ & $14 \pm 0.35$ \\
F5 & $108.6 \pm 0.51$ & Clear & $0.232 \pm 0.05$ & $12 \pm 0.3$ \\
F6 & $109.5 \pm 0.59$ & Clear & $0.241 \pm 0.09$ & $10 \pm 0.32$ \\
F7 & $110.3 \pm 0.6$ & Clear & $0.237 \pm 0.05$ & $11 \pm 0.28$ \\
F8 & $108.4 \pm 0.59$ & Clear & $0.242 \pm 0.09$ & $10 \pm 0.3$ \\
F9 & $110.6 \pm 0.49$ & Clear & $0.256 \pm 0.1$ & $9 \pm 0.25$ \\
F10 & $110.2 \pm 0.58$ & Clear & $0.219 \pm 0.04$ & $13 \pm 0.28$ \\
F11 & $109.4 \pm 0.59$ & Clear & $0.228 \pm 0.05$ & $12 \pm 0.29$ \\
F12 & $108.4 \pm 0.6$ & Clear & $0.236 \pm 0.06$ & $11 \pm 0.3$ \\
\hline
\end{tabular}

Table 4: Evaluation parameters of ramipril FDOF

\begin{tabular}{|c|c|c|c|c|}
\hline Formulation code & $\begin{array}{l}\text { Drug content } \\
(\%)\end{array}$ & $\begin{array}{l}\text { Moisture content } \\
(\%)\end{array}$ & $\begin{array}{l}\text { Folding endurance } \\
\text { (count) }\end{array}$ & Surface $p H$ \\
\hline $\mathrm{F} 1$ & $92.18 \pm 0.5$ & $3.81 \pm 0.09$ & $98 \pm 2$ & $6.6 \pm 0.5$ \\
\hline $\mathrm{F} 2$ & $94.38 \pm 0.51$ & $3.9 \pm 0.09$ & $96 \pm 1$ & $6.79 \pm 0.4$ \\
\hline F3 & $96.21 \pm 0.52$ & $4.5 \pm 0.22$ & $98 \pm 1$ & $6.7 \pm 0.4$ \\
\hline $\mathrm{F} 4$ & $91.18 \pm 0.5$ & $4.69 \pm 0.22$ & $105 \pm 1$ & $6.78 \pm 0.2$ \\
\hline F5 & $93.55 \pm 0.51$ & $4.98 \pm 0.25$ & $100 \pm 4$ & $6.88 \pm 0.4$ \\
\hline F6 & $95.63 \pm 0.52$ & $4.25 \pm 0.1$ & $97 \pm 1$ & $6.81 \pm 0.3$ \\
\hline F7 & $96.48 \pm 0.54$ & $4.32 \pm 0.15$ & $99 \pm 2$ & $6.75 \pm 0.6$ \\
\hline F8 & $97.48 \pm 0.52$ & $4.34 \pm 0.15$ & $104 \pm 1$ & $6.8 \pm 0.3$ \\
\hline F9 & $99.98 \pm 0.69$ & $4.2 \pm 0.12$ & $119 \pm 2$ & $6.94 \pm 0.4$ \\
\hline F10 & $96.12 \pm 0.52$ & $3.99 \pm 0.09$ & $117 \pm 4$ & $6.85 \pm 0.5$ \\
\hline F11 & $96.12 \pm 0.53$ & $3.99 \pm 0.1$ & $117 \pm 5$ & $6.87 \pm 0.6$ \\
\hline F12 & $97.12 \pm 0.54$ & $3.99 \pm 0.11$ & $117 \pm 6$ & $6.89 \pm 0.7$ \\
\hline
\end{tabular}

\section{Thickness of Ramipril FDOF}

The thickness of all twelve formulations ranged between $0.22 \pm 0.04$ to $0.25 \pm 0.10 \mathrm{~mm}$, with highest thickness observed for F9 with low standard deviation values. Keeping polymer concentration constant in all formulations, the results indicate that low concentration of the super disintegrants lead to thinner film, while higher concentration lead to increase in thickness of the film (Table 3).

\section{Disintegration Time (DT) of Ramipril FDOF}

The DT of all ramipril FDOF formulations ranged between 9 to 15 seconds (Table 3). Formulation F9 exhibited minimum DT of 9 seconds, which is sought-after for rapid onset of action. The results indicate that increase in concentration of superdisintegrant decreases the DT (Fig. 3).

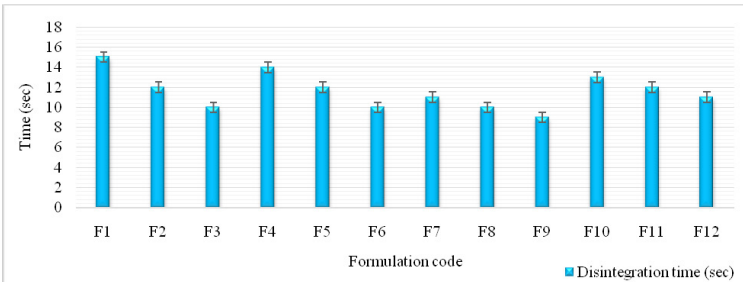

Fig. 3: Disintegrating time of ramipril FDOF (F1-F12)

\section{\% Drug Content}

The \% drug content for all ramipril FDOF formulations indicated that the drug was distributed uniformly throughout the film and ranged between $91.18 \pm 0.5$ to $99.98 \pm 0.69 \%$ with the highest for $\mathrm{F} 9$, as given in Table 4 .

\section{\% Moisture Content}

The \% moisture content of all ramipril FDOF evaluated and ranged between $3.81 \pm 0.09$ to $4.98 \pm 0.25 \%$ (Table 4 ). 


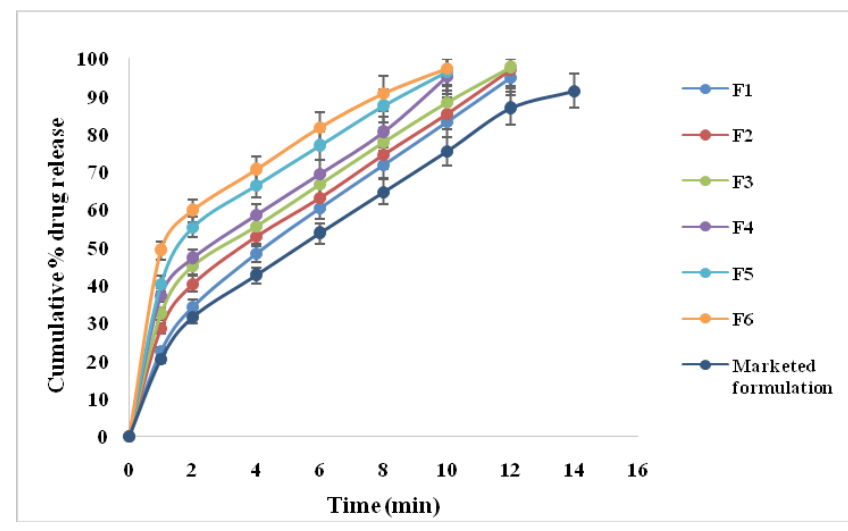

Fig. 4: In vitro drug release profile of marketed formulation of ramipril FDOF (F1-F6)

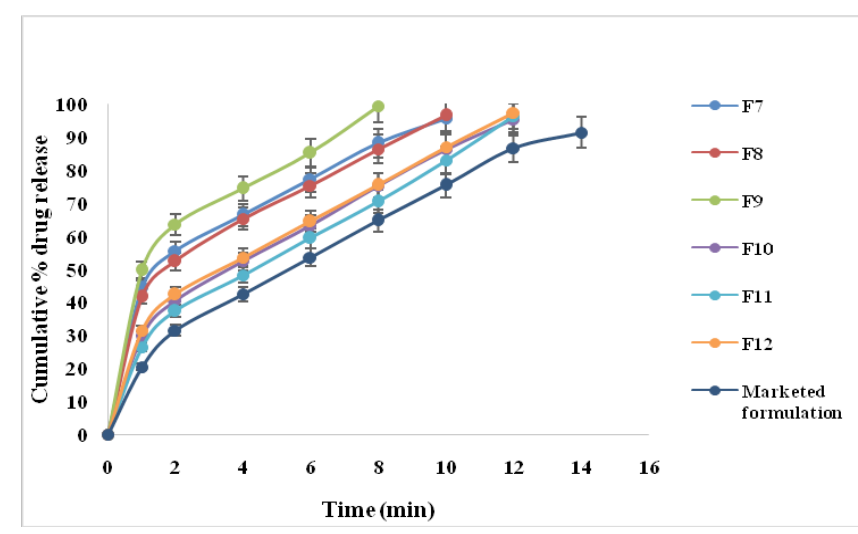

Fig. 5: In vitro drug release profile of marketed formulation and ramipril FDOF (F7-F12)

\section{Folding Endurance}

The folding endurance of each ramipril FDOF was determined and found within the satisfactory range of $96 \pm 1$ to $119 \pm 2$, and shown in Table 4, with the highest value of 119 for F9.

\section{Surface $p H$}

The surface $\mathrm{pH}$ all ramipril FDOF ranged between $6.6 \pm 0.5$ to $6.94 \pm 0.4$, and shown in Table 4 , with the highest value of 6.94 exhibited by F9.

\section{Tensile Strength and Percent Elongation}

The results demonstrate that optimized ramipril FDOF formulation (F9) exhibited better tensile strength of $11.6 \mathrm{~g} / \mathrm{cm}^{2}$ and modest \% elongation of 9.8 , which is attributed to film-forming polymers.

\section{In vitro Drug Dissolution Study of Ramipril FDOF}

The dissolution data of $\mathrm{F} 1$ to $\mathrm{F} 12$ is graphically represented in Figs 4 and 5, and all formulations released $>95 \%$ of drug within 12 minutes. The optimized formulation (F9) shows highest drug release of $99.36 \pm 0.52 \%$ by the end of 8 minutes. It is very clear from the results that the release profile of film formulation using $\beta$-CD has enormously enhanced the solubility of ramipril, and therefore, increased drug release of films, when compared

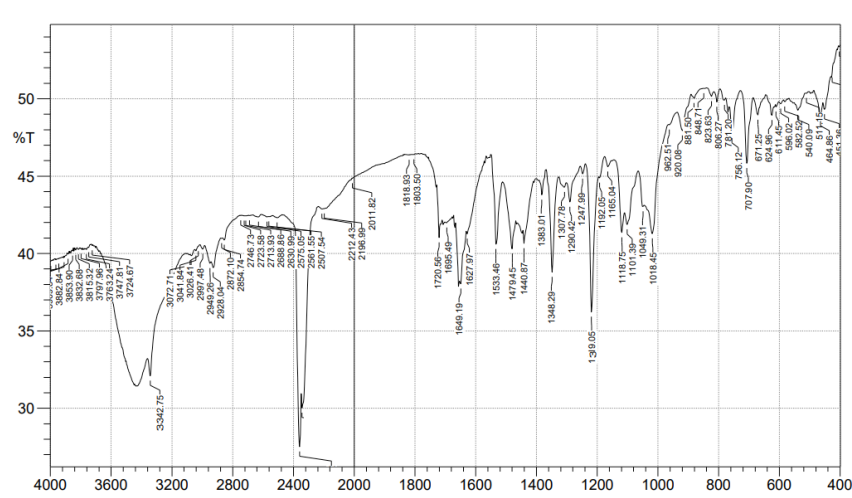

Fig. 6: FTIR of ramipril pure drug

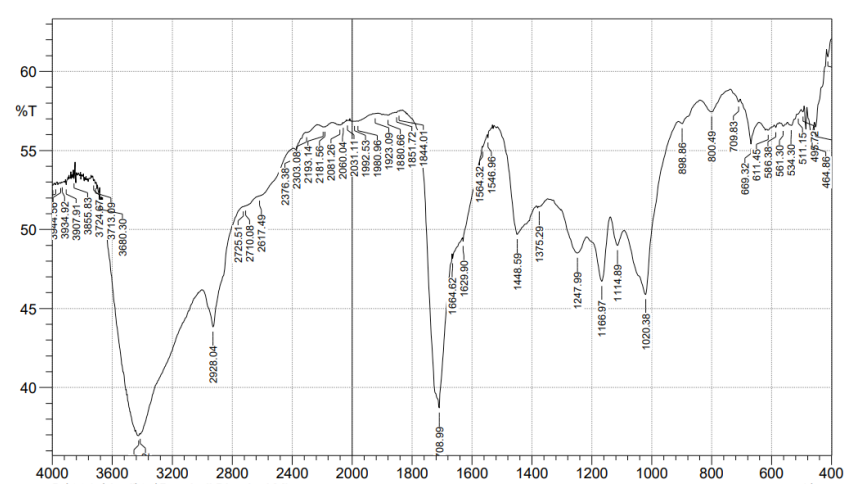

Fig. 7: FTIR of ramipril FDOF (F9)

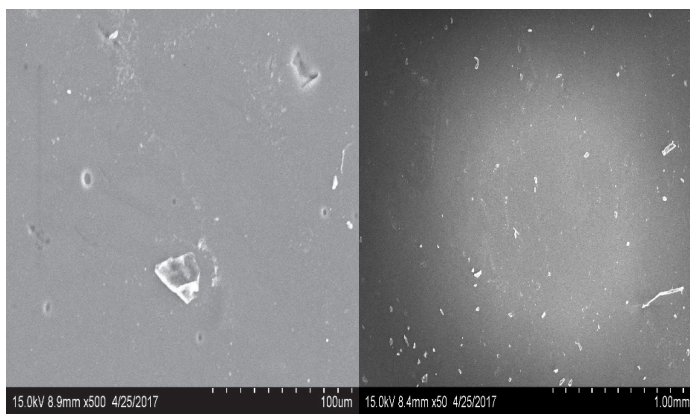

Fig. 8: SEM of ramipril FDOF (F9)

to marketed formulation ( $91.43 \%$ in 15 minutes). As the concentration of the superdisintegrants increased, it resulted in decreasing DT, which in turn enhanced the drug dissolution accordingly.

\section{Drug Excipient Compatibility Study}

The existence of characteristic absorption bands of ramipril pure drug (Fig. 6) and ramipril FDOF optimized formulation (F9) (Fig. 7) demonstrate the presence of no interaction amongst drug and excipients.

\section{SEM Studies}

SEM of ramipril FDOF confirms that surface is rough, uneven with spherical pits with no particles in it suggesting the existence of drug in dissolved state in the polymer. The data ensures the loss of crystallinity of ramipril during formulation (Fig. 8). 
Puttaswamy Nirmala

Table 5: Stability studies of optimized formulation (F9) stored at $40 \pm 2^{\circ} \mathrm{C} / 75 \pm 5 \% \mathrm{RH}$

\begin{tabular}{lll}
\hline Retest time (days) & Drug content (\%) & $\begin{array}{l}\text { In vitro drug release } \\
\text { profile (\%) }\end{array}$ \\
\hline 0 & $99.98 \pm 0.69$ & $99.36 \pm 0.52$ \\
30 & $99.38 \pm 0.26$ & $98.85 \pm 0.63$ \\
60 & $98.79 \pm 0.62$ & $98.12 \pm 1.64$ \\
90 & $98.08 \pm 0.39$ & $97.96 \pm 1.59$ \\
120 & $97.79 \pm 0.17$ & $97.75 \pm 2.48$ \\
180 days & $97.22 \pm 0.53$ & $97.1 \pm 2.43$ \\
\hline
\end{tabular}

\section{Stability Study of Optimized Ramipril FDOF (F9)}

Optimized formulation subjected to stability study for 6 months, analyzed for drug content, and drug release periodically conclude that F9 is stable, retained its original properties with minute insignificant variations (Table 5).

\section{Discussion}

The FDOF of ramipril and $\beta$-CD complexes were formulated successfully by solvent casting technique for immediate action and patient compliance. Results obtained showed that introducing $\beta$-CD significantly increased solubility of ramipril, and in turn, enhanced the drug release with highest drug release for F9 (99.36 $\pm 0.52 \%)$ within 8 minutes, compared to marketed formulation. Concentration of the super-disintegrants also showed significant effect on drug release accordingly. An increase in super-disintegrants concentration decreased the DT and increased drug release. All other evaluation parameters were found within satisfactory range for all 12 ramipril FDOFs. Overall preparation was simple, reproducible, cost-effective, and has potential for consideration for ramipril drug delivery with enhanced solubility, drug release, and bypassed first-pass metabolism.

\section{REFERENCES}

1. Parkash V, Maan S, Deepika, Yadav S, HemLata, Jogpal V. Fast disintegrating tablets: Opportunity in drug delivery system. J Adv Pharm Technol Res. 2011;2(4):223-235.

2. Chaturvedi A, Srivastava P, Yadav S, Bansal M, Garg G, Sharma PK. Fast dissolving films: a review. Curr Drug Del. 2011;8(4):373-380.

3. Nagaraju T, Gowthami R, Rajashekar M,Sandeep S, Mallesham M,
Sathish D. Comprehensive review on oral disintegrating films. Curr Drug Deliv. 2013;10(1):96-108.

4. Bala R, Khanna S, Pawar P,Arora S. Orally dissolving strips: A new approach to oral drug delivery system. Int J Pharm Investig. 2013;3(2):67-76.

5. Rohan RV, Kumbhar SM, Lade RB, Salunkhe PS, Ubale RH. Dissolution rate enhancement of ramipril by solid dispersion technique. Asian J Pharm Res. 2020;10(1):8-12.

6. Suryawanshi VK, Gidwani B, Verma A, Dubey N, Kaur CD. Formulation and evaluation of ramipril liquisolid compact using novel carrier. Int J Pharm Sci and Res. 2019;10(2):917-925.

7. Dalmora ME, Oliveira AG. Inclusion complex of piroxicam with beta-cyclodextrin and incorporation in hexadecyl trimethyl ammonium bromide based microemulsion. Int J Pharm. 1999;184(2):157-164.

8. Prabhu P, Malli R, Koland M, Vijaynarayana K, D'Souza U, Harish N. Formulation and evaluation of fast dissolving films of levocetirizine dihydrochloride. Int J Pharm Investig. 2011;1(2):99-104.

9. Chaturvedi S, Alim M, Agrawal VK. Solubility and Dissolution enhancement of domperidone using 2-hydroxypropyl$\beta c y c l o d e x t r i n$ by kneading method. Asian J Pharm. 2017;11(3):168-175.

10.Joshi P, Patel H, Patel V, Panchal R. Formulation development and evaluation of mouth dissolving film of domperidone. J Pharm Bioallied Sci. 2012;4(1):S108-109.

11.Dua K, Pabreja K, Ramana MV, Lather V. Dissolution behavior of $\beta$-cyclodextrin molecular inclusion complexes of aceclofenac. J Pharm Bioallied Sci. 2011;3(3):417-425.

12.Vaishali Y,Londhe, Umalkar KB. Formulation development and evaluation of fast dissolving film of telmisartan. Ind J Pharm Sci. 2012;74(2):122-126.

13. Keshavarao KP, Mudit D, Gunashekara K, Anis S, Singh MN, Ajay K. Formulation and evaluation of mouth dissolving film containing Rofecoxib. IRJP2011. 2011;2(3):273-278.

14. Tomar A, Sharma K, Chauhan NS, Mittal A, Bajaj U. Formulation and evaluation of fast dissolving oral film of dicyclomine as potential route of buccal delivery. Int J Drug Dev and Res. 2012;4(2):408-417.

15.Sharma D. Formulation development and evaluation of fast disintegrating tablets of salbutamol sulphate for respiratory disorders. ISRN Pharm. 2013:674507.

16. Zaid A, Ghanem M, Maqboul L, Zaid H, Mahasne A. Biowaiver eligibility of a lower strength ramipril/hydrochlorothiazide immediate release tablets using a new validated hplc analytical method. Drug Res. 2016;66(10):539-546.

17. Mashru RC, Sutariya VB, Sankalia MG, Parikh PP. Development and evaluation of fast dissolving film of salbutamol sulphate. Drug Dev Ind Pharm. 2005;31:25-34.

18. Choudhary DR, Patel VA, Patel HV, Kundawala AJ. Formulation and evaluation of quick dissolving film of levocetirizine dihydrochloride. Int J Pharm and Tech. 2011;3(1):1740-1749.

19. Mishra R, Amin A. Formulation and characterization of rapidly dissolving films of cetirizine hydrochloride using pullulan as a film forming agent. Ind J Pharm Edu Res. 2011;45:75-76. 